\title{
Katherine Lunn-Rockliffe, Tristan Corbière and the Poetics of Irony
}

\section{Alessandra Marangoni}

\section{(2) OpenEdition}

\section{Journals}

\section{Edizione digitale}

URL: http://journals.openedition.org/studifrancesi/9629

DOI: 10.4000/studifrancesi.9629

ISSN: 2421-5856

\section{Editore}

Rosenberg \& Sellier

\section{Edizione cartacea}

Data di pubblicazione: 1 décembre 2007

Paginazione: 688

ISSN: 0039-2944

\section{Notizia bibliografica digitale}

Alessandra Marangoni, «Katherine Lunn-Rockliffe, Tristan Corbière and the Poetics of Irony», Studi

Francesi [Online], 153 (LI | III) | 2007, online dal 30 novembre 2015, consultato il 12 janvier 2021. URL: http://journals.openedition.org/studifrancesi/9629; DOI: https://doi.org/10.4000/studifrancesi.9629

Questo documento è stato generato automaticamente il 12 janvier 2021.

\section{cc)}

Studi Francesi è distribuita con Licenza Creative Commons Attribuzione - Non commerciale - Non opere derivate 4.0 Internazionale. 


\title{
Katherine Lunn-Rockliffe, Tristan Corbière and the Poetics of Irony
}

\author{
Alessandra Marangoni
}

\section{NOTIZIA}

KATHERINE LUNN-ROCKLIFfE, Tristan Corbière and the Poetics of Irony, Oxford, Clarendon Press («Oxford Modern Languages and Literature Monographs»), 2006, pp. 236.

1 Questo studio riconosce nelle Amours jaunes di Corbière (rivelato al pubblico dai Poètes maudits di Verlaine) un nuovo uso dell'ironia, alla base della rivoluzione del linguaggio poetico degli anni 1870. Questa nuova ironia, di cui Baudelaire e Flaubert sono gli iniziatori rispettivamente in poesia e nel romanzo, consiste in un misto di oralità, citazione, senso di spaesamento che segnerà, per loro stessa dichiarazione, poeti come Laforgue, Pound ed Eliot. L'A. esplora congiuntamente ambiguità della poesia e ambiguità dell'ironia, poiché nella seconda metà dell'ottocento l'ironia è più di un mero tropo. L'ironia di Corbière non rivela infatti più la reversibilità e leggibilità dell'ironia classica, così come intesa da R. Barthes in S/Z. Trattasi, ormai, di un'ironia polifonica che intacca il soggetto lirico tradizionale mediante una proliferazione di parlanti e parlate. Il dialogismo bachtiniano è tra gli apporti critici maggiormente messi a frutto. Il picco di quest'ironia polifonica è rinvenuto nella settima e ultima sezione delle Amours jaunes, «Rondels pour après»: sei poesie (intese come sequenza) tra le più elusive ed enigmatiche della raccolta, per l'uso di proverbio e canzone popolare $\mathrm{e}$ per la mescolanza o dissonanza di serio e triviale. Il lavoro di analisi è sempre supportato da una buona conoscenza del contesto letterario ottocentesco. 